\author{
NILAI-NILAI PENDIDIKAN ISLAM \\ DALAM KARYA-KARYA KH. R. ASNAWI \\ (Tela'ah Atas Kitab Jawab Soalipun Mu'taqod, Fasalatan, Syi'iran Nasehat)
}

\title{
NUR KHOSI'IN
}

Dosen Institut Pesantren Mathali'ul Falah Pati

Email: n.khosiin@yahoo.co.id

\begin{abstract}
This research is focus direction to study about Islamic education values in the KH. R. Asnawi field trip, wich written in the Jawab Soalipun Mu'taqod, Fsalatan and Syi'iran Nasehat holy books. Researcher is tried to bring interpretation toward KH. R. Asnawi think up with looking method bis harmony and determine rationale. In the KH. R. Asnawi psychology contemplation and history it's turn up initial by KH. R. Asnawi field trip. From this holy book too virified about values relevance with Islamic education goal. Researcher used the type of literature research to study in a dept and intensive manner about meaning which consist from that study with to do research approach according to interpretative-descriptive.
\end{abstract}

Keywords: Values, Islamic Education, KH. R. Asnawi Field Trip.

\begin{abstract}
Abstrak
Penelitian ini diarabkan pada fokus kajian tentang nilai-nilai pendidikan Islam yang ada dalam karyakarya KH. R. Asnawi, yang tertulis dalam kitab Jawab Soalipun Mu'taqod, Fsalatan dan Syiiran Nasebat. peneliti mencoba memberikan interpretasi terbadap pemikiran KH. R. Asnawi dengan cara melihat keselarasannya dan menetapkan inti pemikiran yang mendasar. Ini Ditinjau dari psikologi KH. R. Asnawi dan sejarah awal munculnya karya-karya KH. R. Asnawi. Dari kitab ini juga diteliti mengenai relevansi nilai-nilai tersebut dengan tujuan pendidikan Islam. Peneliti menggunakan jenis penelitian literatur untuk. mempelajari secara intensif dan mendalam tentang makna yang terkandung dari kajian itu serta melakukan pendekatan penelitian secara deskriptifinterpretatif.
\end{abstract}

Kata Kunci: Nilai-Nilai, Pendidikan Islam, Karya KH. R. Asnawi. 


\section{A. Pendahuluan}

KH. R. Asnawi adalah seorang tokoh agama terkenal di Kudus, ia merupakan keturunan dari Sunan Kudus yang ke-14. Setelah menunaikan ibadah haji yang kedua, namanya mulai dikenal di Kudus sebagai penyebar aliran Ablu Al-Sunnah Wa Al-Jama'ah yang mengikuti ajaran al-Asyari dan al-Maturidi. Ia mempunyai peninggalan yang bermanfaat terhadap dunia pendidikan Islam, hal ini dapat dilihat dari lahirnya madrasah qudsiyah dan pondok pesantren Roudhoh at-Tholibin yang sampai sekarang masih aktif sebagai tempat berlangsungnya proses pendidikan Islam, serta mempunyai karya-karya kitab yang masih dipergunakan dikalangan pelajar Jawa, diantaranya kitab Jawab Soalipun Mu'taqad dan Fasholatan yang sampai sekarang masih dibuat materi pelajaran di berbagai madrasah di daerah Kudus dan sekitarnya, serta Syi'iran Nasehat yang menerangkan tentang akhlak. Dalam hal ini, pendidikan pada hakekatnya merupakan suatu upaya mewariskan nilai-nilai yang akan menjadi penolong dan penentu dalam menjalani kehidupan dan sekaligus untuk memperbaiki nasib dan peradaban umat manusia. ${ }^{1}$

Pendidikan merupakan sistem dan cara meningkatkan kualitas hidup manusia dalam segala aspek kehidupan manusia, dalam sejarah umat manusia, hampir tidak ada kelompok manusia yang tidak menggunakan pendidikan sebagai alat pembudayaan dan peningkatan kualitasnya, sekalipun dalam masyarakat yang masih terbelakang/ primitif. $^{2}$

Pendidikan bagi kehidupan umat manusia merupakan kebutuhan mutlak yang harus dipenuhi sepanjang hayat. Tanpa pendidikan sama sekali mustahil suatu kelompok manusia dapat hidup berkembang sejalan dengan aspirasi (cita-cita) untuk maju, sejahtera dan bahagia menurut konsep pandangan hidup mereka.

Untuk memajukan kehidupan mereka itulah, maka pendidikan menjadi sarana utama yang perlu dikelola secara sistematis dan konsisten berdasarkan berbagai pandangan teoritikal dan praktikal sepanjang waktu sesuai dengan lingkungan hidup manusia itu sendiri. Manusia adalah makhluk yang dinamis dan bercita-cita ingin meraih

\footnotetext{
${ }^{1}$ Mansur, Dirkursus Pendidikan Islam, (Yogyakarta: Global pustaka), 2001, hlm. 1.

${ }^{2}$ Hujair AH. Sanaky, Paradigma Pendidikan Islam: Membangun Masyarakat Indonesia, (Yogyakarta: Safiria Insania Press dan MSI), 2003, hlm. 4.
} 
kehidupan yang sejahtera dan bahagia, baik lahiriah maupun rohaniah, duniawi maupun ukhrowi. $^{3}$

Manusia hadir di dunia ini adalah sebagai khalifah atau wakil Allah yang bertugas melaksanakan kehendak-Nya. Tugas manusia terbagi menjadi dua yaitu: tugas dunia dan tugas akhirat. Manusia yang mampu melaksanakan tugasnya itu ialah hamba Allah yang akan mencapai tujuan hidupnya yakni bahagia dunia dan akhirat. Karena itulah, KH. R. Asnawi mengarahkan., dan membimbing manusia lewat karya-karyanya agar menjadi ahli ibadah (abid), yakni manusia yang mampu melaksanakan tugasnya sebagai makhluk individu pada Allah dan tugasnya sebagai makhluk sosial kepada sesama manusia, sehingga tercapailah tujuan kebahagiaan di dunia maupun di akhirat.

Namun bagaimanapun juga, untuk mencapai suatu tujuan haruslah ada jembatan yang menuju ke sana. Sedangkan jembatan yang menghubungkan kepada tujuan tersebut ialah pengajaran atau pendidikan, sekaligus melibatkan komponennya, diantaranya kurikulum atau materi pendidikan yang bersumber pada al-Qur'an dalam upaya pembentukan kepribadian muslim yang meraih kebahagiaan di dunia dan di akhirat, dengan pendidikan keimanan, pendidikan ibadah, serta pendidikan akhlak.

Adapun prioritas pendidikan Islam yang bersumber pada al-Qur'an dalam upaya pembentukan kepribadian muslim ialah :

1. Pendidikan Keimanan Kepada Allah

Sebagaimana firman Allah dalam surat Luqman ayat 13, yang artinya: "Dan (ingatlah) ketika Luqman berkata kepada anaknya, diwaktu ia memberi pelajaran kepadanya: "Hai anakku, janganlah kamu mempersekutukan Allah, sesungguhnya mempersekutukan (Allah) adalah benar-benar kedzaliman yang nyata".

2. Pendidikan Akhlak Karimah

Sebagaimana firman Allah dalam surat Luqman ayat 18, yang artinya: "Dan janganlah kamu memalingkan mukamu dari manusia (karena) sombong dan janganlah kamu berjalan di muka bumi dengan angkuh. Sesungguhnya Allah tidak menyukai orang-orang yang sombong lagi membanggakan diri”.

3. Pendidikan Ibadah

\footnotetext{
${ }^{3}$ Fuad Ikhsan, Dasar-Dasar Kependidikan, (Jakarta: Rineka Cipta), 2005, hlm.3.
} 
Pendidikan yang pertama untuk dilakukan adalah pembentukan keyakinan kepada Allah yang diharapkan dapat melandasi sikap, tingkah laku dan kepribadian anak didik. Iman merupakan dasar, dan realisasi dari iman adalah Islam, konsekuensi dari iman dan Islam adalah ihsan, serta manifestasi dari iman, Islam dan ihsan adalah taqwa. ${ }^{4}$

Sebagaimana firman Allah dalam surat Luqman ayat 17, yang artinya: "Hai anakku, dirikanlah salat dan suruhlah (manusia) mengerjakan yang baik dan cegahlah (mereka) dari perbuatan yang mungkar dan bersabarlah terhadap apa yang menimpa kamu, sesungguhnya yang demikian itu termasuk hal-hal yang diwajibkan (oleh Allah)."

Asnawi adalah seorang ulama yang menjadi panutan oleh masyarakat Kudus. Meskipun Asnawi tidak banyak meninggalkan karya, namun beberapa kitabnya sangat signifikan dan populer di kalangan pelajar Jawa, khususnya para pemula. Di antaranya kitab Jawab Soalipun Mu'taqod yang menerangkan tentang pengertian iman, pengertian ma'rifat, sifat-sifat bagi Allah dan Rasul beserta dalil-dalilnya, yang kesemuanya tergabung dalam kalimat لاله الا الله محمد رسول الله pada awal munculnya diterbitkan, kitab Jawab Soalipun Mu'taqad ini di jadikan sebagai mata pelajaran tauhid di berbagai madrasah ibtidaiyyah dibagian pantura, yang meliputi Demak, Jepara, Kudus, Pati, Juwana dan Rembang. Hal ini disebabkan karena, kitab ini mudah dipahami bahasanya (menggunakan bahasa Jawa) dan mudah untuk dihafalkan bagi pelajar Jawa yang masih dalam tahapan pemula. Kitab Fasalatan, kitab ini menerangkan tentang pentingnya salat lima waktu, dan tata cara bersuci, tata cara salat dari bacaannya maupun gerakannya, serta menerangkan tentang salat-salat sunat seperti salat rawatib, tahajud, dhuha, istisqo', gerhana dan lain-lain.

Kitab Fasalatan ini disusun atas dasar permintaan dari sebagian kaum muslimin Kudus sebagai sebuah amalan yang menurutnya sangat penting di dalam kehidupan sehari-hari sebagai kewajiban seorang muslim terhadap sang khaliq, dan selanjutnya kitab tersebut dijadikan sebagai materi pelajaran di madrasah-madrasah daerah Kudus dan sekitarnya. Syiiran Nasehat, Syiiran ini berbentuk nadloman berbahasa Jawa,

\footnotetext{
${ }^{4}$ Mahmud a Nasir, 1991, ISLAM,konsepsi dan sejarabnya, (Bandung: Remaja Rosda Karya).
} 
didalamnya syi'iran ini menerangkan tentang akhlak manusia terhadap Allah, nabi dan sesama manusia, serta menerangkan tentang akhlak Mahmudab dan Madzmumah.

Kitab Syi'iran nasehat ini, ditulis Asnawi kira-kira pada zaman penjajahan Belanda, sebagai rasa peringatan atas rusaknya moral yang dibawa oleh kaum kolonial. Hal ini bermula dari refleksi atas keadaan pada zaman itu, dimana bangsa Indonesia sangat tertekan oleh kaum kolonial yang dilengkapi dengan pelecahan-pelecahan moral yang merajalela, di antaranya terjadi di depan masjid menara Kudus. Akhirnya Asnawi menggoreskan penanya dan terciptalah Syiiran Nasehat.

\section{B. Metode Penelitian}

Jenis Penelitian yang penulis lakukan termasuk dalam jenis penelitian literatur. Pendekatan dalam penelitian ini menggunakan pendekatan deskriptif, interpretatif, yaitu usaha untuk menggambarkan penafsiran dari karya-karya KH. R. Asnawi. Sumber data terdiri atas sumber data primer seperti kitab jawab soalipun mu'taqod, Fasalatan dan syïiran nasehat, sedangkan sumber data sekunder berupa:

a. Buku dan literatur tentang K.H.R. Asnawi Kudus, seperti intelektual pesantren, perhelatan agama dan tradisi karya Abdurrahman Mas'ud.

b. Buku-buku yang menerangkan tentang pendidikan Islam, pendidikan keimanan, pendidikan ibadah, dan pendidikan akhlak.

c. Teknik pengumpulan data menggunakan metode dokumentasi dan metode interview. Teknik analisis data terdiri atas, analisis hermeneutik psikohistoris yaitu dengan cara memahami makna yang terkandung dalam teks, ditinjau dari psikologi pengarangnya dan sejarah awal munculnya teks tersebut. ${ }^{5}$ analisis deskriptif yaitu dengan cara memindahkan dari hasil pemahaman peneliti kepada pembaca dengan cara merinci berbagai objek.

d. Adapun langkah-langkah yang dilakukan dalam penelitian ini adalah peneliti membaca, mencermati, dan memahami serta mendeskripsikan karya-karya $\mathrm{KH}$.

R. Asnawi, lalu peneliti mencoba memberikan interpretasi terhadap pemikiran KH. R. Asnawi dengan cara melihat keselarasannya dan menetapkan inti

${ }^{5}$ Komaruddin Hidayat, Memahami Bahasa Agama: Sebuah Kajian Hermeneutika, (Jakarta: Paramadina), 1996, hlm. 129. 
pemikiran yang mendasar. Ditinjau dari psikologi KH. R. Asnawi dan sejarah awal munculnya karya-karya KH. R. Asnawi.

\section{Pengertian Pendidikan Islam}

Di dalam masyarakat Islam sekurang-kurangnya terdapat tiga istilah yang digunakan untuk menandai pengertian pendidikan Islam, yaitu tarbiyah (تربيه), ta'lim (تعلم), ta'dib (تأديب). Istilah tarbiyah, menurut para pendukungnya, berakar pada tiga kata. Pertama, kata raba, yarbu (ربا, يربو) yang berarti bertambah dan tumbuh. Kedua, kata rabiya, yarba (ربي, يربى) yang berarti tumbuh dan berkembang. Ketiga, kata Rabba Yarubbu (ربّ, يرب) yang berarti memperbaiki, menguasai, memimpin, menjaga dan memelihara. ${ }^{6}$

'Abdurrahman Al-Nahlawi salah seorang pengguna istilah tarbiyah, berpendapat bahwa pendidikan berarti memelihara fitrah anak. Menumbuhkan seluruh bakat dan kesiapannya. Mengarahkan fitrah dan seluruh bakatnya agar menjadi baik dan sempurna, serta bertahap dalam prosesnya.

Istilah lain yang digunakan untuk menunjukkan pengertian pendidikan Islam adalah ta'lim. Jalal, salah seorang yang menawarkan penggunaan istilah ini, mengemukakan konsep-konsep pendidikan yang terkandung didalamnya sebagai berikut :

Pertama, ta'lim adalah proses pembelajaran secara terus menerus sejak manusia lahir melalui pengembangan fungsi-fungsi pendengaran, penglihatan, dan hati. Kedua, proses ta'lim tidak berhenti pada pencapaian. Pengetahuan dalam wilayah (domain) kognisi semata, tetapi terus menjangkau wilayah psikomotor dan afeksi. Pengetahuan Press), 2004.

${ }^{6}$ Moh Rosyid, , Ilmu Pendidikan [Sebuah Pengantar] Menuju Hidup Prospektif, (Semarang: UPT.Unnes 
yang berada dalam batas-batas wilayah kognisi tidak akan mendorong seseorang untuk mengamalkannya, dan pengetahuan semacam itu biasanya diperoleh atas dasar prasangka atau taklid.

Serta istilah Ta'dib, istilah Ta'dib untuk menandai pengertiam pendidikan Islam ditawarkan oleh al-Attas. Istilah ini berasal dari kata adab dan pada pendapatnya, berarti pengenalan dan pengakuan tentang hakikat bahwa pengetahuan dan wujud bersifat teratur secara hirarkis sesuai dengan berbagai tingkatan dan derajat tingkatannya serta tentang tempat seseorang yang tepat dalam hubungannya dengan hakikat itu serta dengan kapasitas dan potensi jasmani intelektual, maupun rohani seseorang. Dengan pengertian ini, kata adab mencakup pengertian 'ilm dan 'amal.

Adapun di antara isi dari pendidikan islam adalah pendidikan keimanan, pendidikan ibadah dan pendidikan akhlak. Landasan dasar pendidikan Islam utamanya terdiri atas tiga macam, yaitu Al-Qur'an, As-Sunnah, Ijtihad.

\section{a. Tujuan Pendidikan Islam}

1. Al-Ghazali, berpendapat sebagaimana yang dikutip oleh Fatiyah Hasan Sulaiman, bahwa tujuan pendidikan Islam ialah:

$$
\text { الكمال الانسان الذي غايته التقرب من الله ثم الكمال الانسانى الذي غايته سعادة }
$$

Artinya : "Kesempurnaan manusia yang berujung taqorrub (mendekatkan diri) kepada Allah dan kesempurnaan yang berujung kepada kebahagiaan dunia dan kebahagiaan akhirat (sulaiman, terj. Fathurrahman, 1986: 24).

Dari kedua tujuan di atas dapat dipahami bahwa tujuan pendidikan versi al-Ghazali tidak hanya bersifat ukhrowi (mendekatkan diri kepada Allah), sebagaimana yang dikenal dengan kesufiannya, tetapi juga bersifat duniawi. Karena itu al-Ghazali memberi ruang yang cukup luas dalam sistem pendidikannya bagi perkembangan duniawi. Namun dunia, hanya dimaksudkan sebagai menuju kebahagiaan hidup di alam akhirat yang lebih kekal.

\section{Biografi Intelektual KH. R. Asnawi dan Karya-Karyanya}


KH. R. Asnawi dilahirkan di Damaran, daerah di belakang menara Kudus pada tahun $1281 \mathrm{H} / 1864 \mathrm{M}$, dan meninggal pada tahun 1959. Sebagai seorang kiai, kepeduliannya dalam pendidikan Islam membuat Asnawi juga mengajarkan ilmunya pada masyarakat Kudus dengan metode dan media atau sarana dan prasarana sesuai dengan karakter ke-ulama-annya, di antaranya dengan Madrasah, Pondok Pesantren, Majlis Ta’lim.

Diantara karya-karyanya adalah Fasholatan (1954) tentang fiqh, Jawab soalipun mu'taqad yang lebih populer dengan nama mu'taqad seked, shalawat asnawiyah, syi'iran nasehat, puisi kemerdekaan, sya'ir isra' mi'raj, do'a untuk pengantin, syariat Islam (berbahasa Arab) tentang fiqh, terjemahan jurumiyah tentang tata bahasa Arab. Sayangnya dua yang terakhir ini tidak diterbitkan dan tidak pula berhasil di koleksi oleh anak-anaknya.

\section{E. Sekilas Tentang Kitab Jawab Soalipun Mu'taqod, Fasalatan dan Syi'iran Nasehat}

1. Jawab Soalipun Mu'taqod

Kitab jawab soalipun mu'taqad karya KH. R. Asnawi lebih populer di sebut yang Mu'taqad Seked, karena di dalamnya berisi tentang Mu'taqad Seked, yaitu 41 sifat-sifat bagi Allah dan 9 sifat-sifat bagi para rasul.

2. kitab Fasalatan

Adapun topik bahasan pada kitab fasalatan ini adalah tentang bacaan adzan, jawaban adzan, bacaan iqomat, tata cara wudhu, hal-hal yang membatalkan wudhu, tata cara salat, orang yang kewajiban salat, syarat syahnya salat, rukun-rukun salat, dzikiran atau wiridan sesudah salat, perkara yang membatalkan salat, salat jumat, salat rawatib, salat tarawih dan witir, salat dhuha, salat tasbih, salat idul fitri dan idul adha, salat jamaah dan qashar, salat janayah, salat istikharah, salat istisqa', salat khusuf dan kusuf, dan salat tahajud. Pada bagian akhir adalah khotimah, yang berisi tentang amalan-amalan.

2. Syi'iran Nasehat

Syi'iran nasehat ini berisi tentang akblak madzmumah dan akblak mahmudah. 


\section{F. Nilai-Nilai Pendidikan Islam Dalam Karya-Karya Kh.R Asnawi Dan Relevansinya Dengan Tujuan Pendidikan Islam}

Sebelum KH. R. Asnawi menjelaskan tentang sifat-sifat Allah dan Rasulnya yang ada 50, terlebih dahulu ia menerangkan tentang tanda-tanda orang yang mempunyai agama, seperti yang tertulis pada halaman 2 keterangan dari Imam Nawawi, orang mempunyai agama itu ada empat macam tanda yaitu menjalankan ibadah dengan niat yang ikhlas, menjalankan perintah yang difardhukan Allah, menjauhi perkara yang diharamkan Allah, menetapi I'tiqodnya Ablu As-Sunnah, yaitu mu'taqod yang dijalankan oleh Imam Asy'ari atau Imam al-Maturidi.

Menurut keterangan nomor empat (4), yang mana Ablu As-Sunnah sudah menggunakan dengan mu'taqodnya yang dijalankan oleh Imam Asy'ari atau Imam alMaturidi, dan kedua imam tersebut membuat dalil dari sifat-sifat Allah dengan dalil aqli kecuali sifat كَلَاِْ بَصَرَ, yَمَع yang menggunakan dalil al-Qur'an. Jadi apabila ada mu'taqod yang kesemua dalilnya menggunakan al-Qur'an berarti itu sudah keluar dan tidak menurut peraturan ahlu as-Sunnah.

Dari uraian diatas dapat dipahami, bahwa mu'taqod yang dipergunakan oleh Asnawi adalah mu'taqod yang dijalankan oleh Imam Abu Hasan al-Asy'ari dan Abu Mansur al-Maturidi. Pada bagian selanjutnya Asnawi menerangkan tentang pengertian ma'rifat.

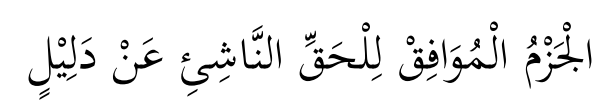

Artinya: "I'tiqodnya hati yang mantap dan cocok dengan kebenaran yang datangnya dari dalil."

Dalam hal ini, menurut pandangan Asnawi, mantap adalah pengecualian dari I'tiqod yang ragu-ragu, sedangkan cocok dengan kebenaran adalah pengecualian dari I'tiqod yang mantap dan sesuai dengan perkara salah dan datang dari dalil, maksudnya adalah mengecualikan I'tiqod yang mantap dan sesuai dengan kebenaran yang tidak disertai dalil, atau disebut taqlid (ikut-ikutan). 
Dari uraian di atas dapat dipahami, bahwa ma'rifat menurut Asnawi adalah bersatunya antara الجزم (mantapnya hati), موافق (cocok/ sesuai) dan دليل (dalil).

Selanjutnya, KH. R. Asnawi menjelaskan tentang pengertian iman, yaitu :

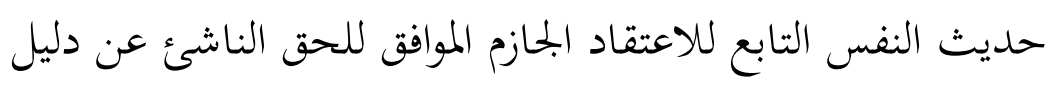

Artinya: "Ucapan hati yang mengikuti pada kemantapan I'tiqod dan sesuai dengan kebenaran, yang kebenaran tersebut datangnya dari dalil”.

Pada bagian awal kitab mu'taqod seket, KH. R. Asnawi menerangkan tentang kewajiban yang pertama kali bagi manusia, yaitu :

Soal : Permulaan kewajiban bagi manusia itu apa?

Jawab : Permulaan kewajiban bagi manusia adalah mengetahui Tuhan

Soal : Apa yang harus kita ketahui tentang Tuhan?

Jawab : Yang harus kita ketahui tentang Tuhan itu sifat-Nya, bukan dzatNya

Kemudian KH. R. Asnawi menerangkan tentang sifat-sifat bagi Allah baik yang wajib, yang muhal atau mustahil maupun yang jaiz yang kesemuanya sifat-sifat Allah itu ada empat puluh satu (41).

Selanjutnya KH. R. Asnawi menerangkan tentang sifat wajib bagi Allah yang diringkas menjadi empat, yaitu sifat Nafsiyah, Salbiyah, Ma'ani dan Ma'nawiyah. Adapun sifat nafsiyah itu ada satu yaitu sifat wujud, sedangkan sifat salbiyah ada lima yaitu Qidam, Baqa', Mukhalafah Lil Khawadisi, Qiyamubu Binafsibi dan Wahdaniyah. Kemudian sifat ma'ani yang ada tujuh, yaitu Qudrah, Iradah, Ilmu, Hayah, Sama', Basar, Kalam, dan terakhir sifat Ma'aniwah yang ada tujuh pula yaitu: Qodiran, Muridan, 'Aliman, Hayyan, Sami'an, Basiran dan Mutakalliman.

Bahasan selanjutnya KH. R. Asnawi menerangkan tentang sifat-sifat bagi Rasul, baik sifat wajib, sifat muhal atau mustahil maupun sifat jaiz yang ada sembilan (9) yaitu sifat wajib bagi rasul terdiri atas Sidiq artinya para Rasul itu jujur, Amanah artinya para 
Rasul itu bisa dipercaya, Tabligh artinya para Rasul itu menyampaikan wahyu, Fatanah artinya para Rasul itu cerdas. Adapun Sifat Mubal bagi Rasul, Kiz̧ib artinya para Rasul itu muhal bohong, Khiyanah artinya para Rasul itu mubal khiyanah (cidero - Jawa), Kitman artinya para Rasul itu muhal menyimpan wahyu, Baladah artinya para Rasul itu muhal bodoh

Dan sifat jaiz bagi Rasul, yaitu Wuqu'u A'radi Al-Basyariyah artinya para Rasul itu boleh ketetapan sifat-sifat manusia, seperti makan, minum, tidur, sakit dan lain-lain.

Kemudian KH. R. Asnawi menjelaskan tentang sifat wajib, muhal dan jaiz bagi Allah yang tergolong dalam sifat istigna' dan sifat iftiqor. Adapun sifat wajib bagi dalam Istigna' itu ada sebelas, yaitu Wujud, Qidam, Baqa' Mukhlafah Li Al Khawadisi, Qiyamubu, Binafsibi, Sama', Basar, Kalam, Sami'an, Basiran, Mutakalliman Dan sifat yang muhal bagi Allah dalam istigna' juga ada sebelas yaitu, Adam, Khudus, Fana', Mumatsalah Li Al Khawadisi, Ibtiyaju Li Goiribi, Samamun, 'Ama, Bukmu, Asammu, A'ma, Abkamu. Sedangkan sifat jaiz bagi Allah itu termasuk dalam kategori sifat istigna’.

Adapun sifat wajib bagi Allah dalam iftiqor itu ada sembilan, yaitu: Hayah, Qudrah, Iradah, Tlmu, Hayyan, Qadiran, Muridan, 'Aliman Dan Wabdaniyat. Sedangkan sifat muhal bagi Allah dalam iftiqor juga ada sembilan, yaitu: Matun, 'Ajæun, Karahah, Jablun, Maitan, 'Ajizan, Karihan, Jabilan, dan Ta'addud.

لاله Selanjutnya KH. R. Asnawi mengumpulkan mu'taqod 41 ke dalam lafadh الاالهّ, adapun alasannya adalah lafadh tersebut menyimpan pada tiga bagian yang diwajibkan bagi orang mukallaf untuk mengetahuinya, yaitu sifat wajib, sifat muhal dan sifat jaiz bagi Allah. Sedangkan mu’taqod 9 itu terkumpul dalam lafadh محمدرسول الله, adapun alasannya adalah Nabi Muhammad sudah ditetapkan oleh Allah menjadi utusan Allah untuk menjelaskan hukum-hukum-Nya. Jadi Nabi Muhammad mempunyai sifat wajib empat, yaitu: Sidiq, Amanah, Tabligh dan Fatanah, dan sifat muhal empat, yaitu: Kidib, Khiyanat, Kitman, Baladah. Dan Nabi Muhammad adalah seorang manusia yang mendapat wahyu dari Allah, maka Nabi Muhammad juga seperti halnya manusia dan 


\section{NUR KHOSI'IN}

beliau juga mempunyai sifat (Arad Al Basyariyah) tetapi Arad Al Basyariyabnya tidak sampai menjadikan cacatannya Nabi Muhammad, seperti gila, ayan dan lain sebagainya.

Adapun dalil yang digunakan KH. R. Asnawi tentang sifat wajib bagi Allah adalah sebagai berikut :

1. Sifat Wujud, dalilnya adalah wujudnya alam (bumi dan langit seisinya) dalam keadaan kokoh dan indah yang bersifat baharu ialah menunjukkan bahwa ada yang membuat, yaitu Allah.

2. Sifat Qidam, dalilnya adalah seumpama Allah tidak bersifat Qidam tentu Allah bersifat Huduts (baru), seandainya Allah baru tentu ada yang memperbaharui, dan seandainya Allah ada yang memperbaharui tentu yang memperbaharui Allah ada yang memperbaharui lagi, begitu juga seterusnya sehingga terjadi daur dan tasalsul, padahal daur dan tasalsul itu mahal, jadi Allah tetap bersifat Qidam.

3. Sifat Baqa', dalilnya adalah seandainya Allah tidak Baqa' pasti Fana' (rusak), seandainya Allah rusak pasti menunjukkan barang yang mungkin wujudnya, seandainya Allah mungkin wujud, pasti menunjukkan sesuatu yang baru, dan seandainya Allah baru, tentunya Allah tidak bersifat Qidam. Padahal tidak bersifatNya Qidam Allah itu muhal, jadi Allah tetap bersifat Baqa'.

4. Sifat Mukhalafah Li Al-Hawadisi, dalilnya adalah seandainya Allah itu sama seperti manusia ataupun makhluk-Nya, maka Allah pasti bersifat baru, padahal sifat baru bagi Allah adalah muhal dan Allah telah bersifat qidam. Jadi Allah bersifat Mukhalafah Li Al-Hawadisi.

5. Sifat Qiyamubu Binafsibi, dalilnya adalah seandainya Allah tidak bersifat Qiyamubu Binafsibi maka Allah tentu membutuhkan tempat untuk ditempati, dan hal tersebut termasuk kategori sifat, padahal sifat tersebut membutuhkan dzat untuk ditempati, sedangkan Allah itu dzat, bukan sifat. Dan apabila Allah butuh pada dzat yang membuat tempat maka Allah adalah baru, padahal Allah muhal bersifat baru. Jadi Allah tetap bersifat Qiyamubu Binafsibi.

6. Sifat Wahdaniyah, dalilnya adalah seandainya Allah tidak Esa, maka Allah berbilang, dan seandainya Allah berbilang, tentu alam (bumi dan langit seisinya) tidak akan 
wujud, karena sifat lemahnya Allah, dan dalam kenyataannya alam sudah jelas-jelas wujud (ada), jadi Allah tetap bersifat Wabdaniyah.

7. Sifat Qudrah, sifat Iradah, sifat 'Ilmu, dan sifat Hayah, adapun dalilnya adalah seandainya Allah tidak bersifat empat tersebut diatas, maka alam (bumi langit seisinya) tentu tidak akan wujud, padahal dalam kenyataannya sudah jelas kalau alam itu ada, jadi Allah tetap bersifat qudrah, iradah, ílmu dan hayah.

8. Sifat sama', basar, dan kalam, adapun dalilnya dari ketiga sifat tersebut menurut KH. R. Asnawi adalah bersumber dari al-Qur'an, al-Hadtis dan ijma' para ulama, yaitu : Al-Qur'an :

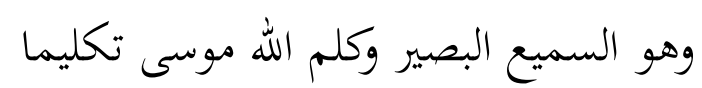

Al-Hadis :

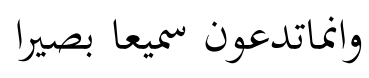

Dan Ijma' para ulama yaitu:

Seandainya Allah tidak bersifat Sama', Basar, dan Kalam, tentunya Allah bersifat yang berlawanan dari ketiga sifat tersebut yaitu sifat tuli, buta dan bisu, dan padahal sifat tuli, buta dan bisu itu muhal bagi Allah, dan hal tersebut tidak dapat dibenarkan menurut akal, jadi Allah tetap bersifat Sama', Basar, dan Kalam.

Adapun dalil dari sifat ma'ani yang sudah disebutkan di atas yaitu Qudrah, Iradah, 'Ilmu, Hayah, Sama', Bashar dan Kalam itu juga menjadi dalil dari sifat Ma'nawiyah, yaitu sifat Qadiran, Muridan, 'Aliman, Hayyan, Sami'an, Basiran dan Mutakalliman.

Di dalam kitab Mu'taqod Seket, Asnawi membahas tentang sifat-sifat Tuhan dengan membagi apa yang wajib, mustahil dan jaiz pada Tuhan.

Sifat-sifat wajib Tuhan dibagi menjadi empat, yaitu Nafsiyah, Salbiyah, Ma'ani dan Ma'nawiyah. Sifat nafsiyah ini adalah sifat Wujud.

Kedua sifat Salbiyah, Sifat Salbiyah ada lima, yaitu: Qidam, Baqa' Mukhalafah Li Al-Hawadis, Qiyamuh Bi Nafsibi, Wabdaniyah

Ketiga sifat Ma'ani, Di antara sifat Ma'ani adalah sifat Qudrah, Iradah, Ilmu, Hayah, Sama', Basar, Kalam. 
Sedangkan sifat yang keempat adalah sifat Ma'nawiyah, yaitu Qodiran, Muridan, 'Aliman, Hayyan, Sami'an, Basiran dan Mutakalliman.

Adapun dalil yang dikemukakan oleh KH. R. Asnawi tentang sifat jaiz Allah adalah seandainya Tuhan wajib membuat sesuatu yang mungkin atau mustahil membuat sesuatu yang mungkin, sehingga mungkin wajib wujudnya atau mungkin mustahil wujudnya. Padahal wujudnya kemungkinan dengan perantara wjaib itu tidak masuk akal. Begitu juga wujudnya kemungkinan dengan perantara mustahil itu pun tidak masuk akan juga. Jadi Tuhan tidak wajib dan tidak mustahil dalam membuat dan berkehendak terhadap sesuatu.

Selanjutnya KH. R. Asnawi mengemukakan dalil aqli terhadap sifat-sifat wajib para Rasul, yaitu:

1. Dalil sifat sidiq adalah seandainya para rasul itu tidak jujur/ berbuat bohong, maka para Rasul tersebut tentukan berbohong terhadap firman-firman Allah, sedangkan Allah telah berfirman yang berbunyi :

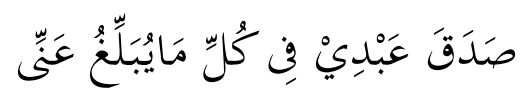

Dan seandainya para Rasul yang sudah ditetapkan oleh Allah akan kebenarannya (kejujurannya) itu berbuat bohong, maka Allah pun akan berbuat bohong juga. Padahal sudah jelas-jelas jika Allah tidak akan berbuat bohong, jadi para Rasul tetap bersifat sidiq.

2. Dalil sifat amanah adalah seandainya para Rasul itu berbuat dusta dan melakukan perkara-perkara yang haram dan makruh, tentunya haram dan makruh itu menjadikan amal kebajikan, karena kita diperintah untuk ikut melakukan sesuatu yang dilakukan oleh para Rasul. Sedangkan Allah tidak pernah memerintah kepada hamba-hamba-Nya untuk melakukan perbuatan yang makruh, apalagi haram. Jadi para Rasul tetap bersifat amanah.

3. Dalil sifat tabligh adalah seandainya para Rasul tidak menyampaikan firman Allah pada umat manusia, maka para Rasul tersebut pasti berbuat dusta, padahal berbuat dusta itu mubal bagi para Rasul, jadi para Rasul tetap bersifat tabligh. 
4. Dalil sifat fatanah adalah seandainya para Rasul itu bodoh, mana mungkin para Rasul akan dapat memenangkan hujjahnya terhadap umat-umat yang durhaka. Padahal al-Qur'an telah menerangkan bahwa para dapat memenangkan hujjahnya terhadap umat-umat yang durhaka, hal inilah yang menjadi bahwa para Rasul itu bersifat fatanah.

Kemudian KH. R. Asnawi menjelaskan dalil tentang sifat jaiz para Rasul, yaitu semua para Rasul selalu naik derajat keluhurannya, dan menerimanya Arad Al-Basyariyah bagi para Rasul itu menjadikan Tingginya kedudukan para Rasul, seperti makan, minum, sakit, meninggal dunia, mendapatkan kerusakan dan lain-lain, yang tidak sampai mengurangi martabatnya, dan agar selain para Rasul merasa tabah, sabar dan tenteram ketika menerima cobaan, sakit, kesusahan dan lain-lain. Karena para Rasul pun yang menjadi kekasih Allah menerima cobaan juga. Bagi orang yang berakal, ia akan mengerti bahwa dunia ini menjadi tempat Ujian Allah kepada kekasihnya, seandainya dunia ini bukan sebagai tempat ujian, maka para kekasih Allah maupun kepalanya para kekasih Allah yaitu Rasulullah SAW tidak akan menerima Arad Al-Basyariyah yang berupa cobaan dan kesusahan di dunia.

Selanjutnya pada bagian akhir, KH. R. Asnawi berpesan kepada kaum muslimin dan muslimat agar menghafalkan sifat-sifat Allah dan Rasul-Nya beserta dalil-dalilnya, dengan harapan menjadikan sababiyah tetapnya iman di dunia sampai akhirat.

Sampai di sini KH. R. Asnawi menyusun kitab tentang keimanan yang diberi judul Jawab Soalipun Mu'taqod, kitab ini berisi tentang sifat-sifat Allah, baik yang wajib, mustahil maupun jaiz, yang jumlahnya adalah 41, dan sifat-sifat para Rasul, baik yang wajib, mustahil, jaiz yang jumlahnya ada 9. Hal ini merupakan bentuk kepedulian KH. R. Asnawi kepada umat Islam rangka pembentukan dan pengembangan keimanan seseorang, agar umat Islam selalu teguh dan kuat imannya.

Dari sini nampaklah bahwa KH.R Asnawi menggunakan teologi dari Asy'ariah, yaitu oleh Abu Abdillah Muhammad Bin Yusuf As-Sanusi(833-895 H/ 1427-1490 M), karna Ia(As-Sanusi) yang menyebarkan konsep teologi sifat-sifat Allah dan RosulNYA,yang dibagi menjadi sifat wajib, sifat muhal dan sifat jaiz. Kemudian sifat wajib 
Allah dikelompokkan menjadi Sifat Nafsiyah, Sifat Salbiyah, Sifat Ma'ani dan Sifat Ma'nawiyah.

Kitab Jawab Soalipun Mu'taqod karya KH.R Asnawi menerangkan tentang pendidikan keimanan, namun pendidikan keimanan yang terdapat di dalamnya hanya sebatas tentang iman pada Allah serta Rosul-NYA, dan itu pun hanya pengenalan tentang sifat-sifat saja, yang meliputi sifat wajib, sifat muhal, dan sifat jaiz. Padahal dalam konsep akidah terdapat 6 macam keimanan atau yang lebih di kenal dengan rukun iman, yaitu iman kepada Allah. Iman kepada Malaikat. Iman kepada Kitab. Iman kepada Rusul. Iman kepada Hari akhir. Iman kepada qada dan qodar.

Jadi, pendidikan keimanan seperti iman pada malaikat, kitab, hari akhir dan qodha' qodar belum diterangkan dalam kitab Jawab Soalipun Mu'taqod. Walaupun KH.R Asnawi belum menerangkan tentang pendidikan keimanan secara keseluruhan, Namun pendidikan keimanan yang terdapat dalam kitab Jawab Soalipun Mu'taqod sangat berarti bagi masyarakat kudus pada zaman itu sampai sekarang, khususnya bagi para anak-anak maupun orang yang tingkat keimanannya masih lemah.

Hal ini sesuai yang tertulis dalam kitab Jawab Soalipun Mu'taqod halaman 4, yaitu tentang kewajiban pertama kali bagi manusia. Dari sinilah KH.R Asnawi merasa perlu menerangkan tentang kewajiban bagi manusia, yaitu mengetahui sifat-sifat Allah, bukan mengetahui dzat-Nya.

Dalam hal ini, pendidikan keimanan merupakan poros pendidikan Islam yang menuntun individu untuk merealisasikan ketaqwaan di dalam jiwa. Pendidikan keimanan tersebut mencakup segala kewajibannya, yaitu beriman kepada Allah, malaikat-Nya, kitab-kitab-Nya, para Rasul-Nya, hari akhir dan qada', qadar-Nya. ${ }^{7}$

Adapun wujud relevansi nilai-nilai pendidikan keimanan dalam kitab Jawab Soalipun Mu'taqod dengan tujuan pendidikan Islam adalah bahwa kitab tersebut berisi tentang keimanan, yaitu iman kepada Allah dan Rasul-rasul-Nya beserta dalil-dalilnya, sedangkan tujuan pendidikan Islam ialah untuk membina dan membimbing fitrah manusia (peserta didik) secara maksimal dan bermuara pada terciptanya pribadi peserta

${ }^{7}$ Munzier, Heri Noer Aly, Watak Pendidikan Islam, (Jakarta: Friska Agung Insani), 2003. 
didik sebagai muslim pari purna (insan kamil), melalui sosok pribadi yang demikian, manusia (peserta didik) diharapkan akan mampu memadukan dan merealisasikan fungsi dari keimanan, ilmu dan amal, agar dapat terbina kehidupan yang harmonis baik di dunia maupun di akhirat.

\section{G. Nilai-nilai Pendidikan Ibadah dalam Kitab Fasalatan dan Relevansinya dengan} Tujuan Pendidikan islam

Kitab Fasalatan adalah merupakan kitab favorit dikalangan awam dan para santri yang tidak memahami bahasa arab. Kitab ini berisikan tentang azan,iqamah, wudhu, tatacara salat, hal-hal yang membatalkan salat, salat jumat dan salat-salat sunnah, di antaranya Rawatib, Tarawih, Witir, Duba, Tasbih, Istisqo' dan lain-lain.

KH. R. Asnawi dalam menyusun sebuah kitab, diberi nama Fasalatan. Hal ini merupakan bentuk kepeduliannya kepada umat Islam khususnya bagi anal-anak, dalam rangka pembentukan kepribadian muslim yang selalu taat dan beribadah pada Allah khususnya dalam hal salat.

Dalam kitab Fasalatan ini KH.RAsnawi menggunakan mąhab Syafi'i, Hal ini dapat dilihat pada fasal rukun wudu yaitu ketika mengusap sebagian kepala, Menurut Syafi'i, ketika mengusap kepala cukuplah sebagian kepala saja, Namun menurut Abu Hanifah paling sedikit mengusap kepala seper empat kepala, Sedangkan menurut Malik dan Ahmad diharuskan mengusap seluruh kepala. Dan pada fasal perkara yang membatalkan wudu yaitu ketika bersentuhan kulit antara laki-laki dan perempuan, serta menyentuh kemaluan. Menurut Syafi'i, bersentuhan kulit antara laki-laki dan perempuan membatalkan wudu kecuali mahramnya, menurut Malik sentuhan dengan ciuman membatalkan wudhu tetapi kalau tidak dengan ciuman tidak membatalkan wudu selagi tidak syahwat, Namun kalau syahwat tetap membatalkan wudu, Sedangkan menurut Abu Hanifah bersentuhan antara laki-laki dan perempuan tidak membatalkan wudu, Karna menurutnya yang dimaksud Lamastum adalah bersetubuh. Pada bahasan tentang menyentuh kemaluan, Syafi'i, Malik, Ahmad dan Daud membatalkan wudu, Namun menurut Abu Hanifah tidak membatalkan wudu.

Kitab fasalatan ini menerangkan tentang pendidikan ibadah, namun di dalamnya hanya menerangkan tentang fasal-fasal salat, padahal pendidikan ibadah didalam islam 
bukan hanya salat saja, melainkan ada pendidikan ibadah yang lain, seperti muamalah, puasa, zakat, haji dan lain sebagainya.

Walaupun KH.R Asnawi belum menerangkan semuanya tentang pendidikan ibadah, tetapi kitab Fasalatan tersebut sangat berarti bagi masyarakat kudus pada zaman itu dan zaman sekarang, khususnya bagi para pemula atau anak-anak, karena menurut KH.R Asnawi pendidikan yang berupa salat itu penting sekali. Ia mengingatkan kepada kaum muslim beserta anak-anaknya untuk selalu menunaikan salat lima waktu, Karna tanpa mengerjakan salat kaum muslim akan merugi.

Adapun wujud relevansi nilai-nilai pendidikan ibadah dalam kitab Fasalatan dengan tujuan pendidikan Islam adalah, bahwa kitab Fasalatan berisi tentang tata cara salat, mulai dari sunnah-sunnah sebelum salat, syarat syahnya salat, perkara yang membatalkan salat dan rukun-rukun salat. Sedangkan tujuan pendidikan Islam harus dikaitkan dengan tujuan hidup manusia, atau lebih tegasnya, tujuan pendidikan Islam adalah untuk menjawab persoalan "Untuk apa kita hidup?," Islam telah memberi jawaban yang tegas dalam hal ini, Allah berfirman :

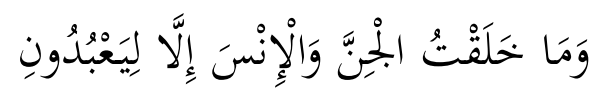

Tujuan hidup seorang muslim dapat digambarkan sebagaimana dengan do'a yang selalu dibaca dalam salat, yaitu :

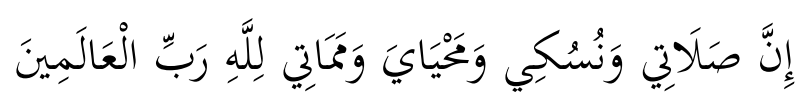

\section{H. Nilai-Nilai Pendidikan Akhlak dalam Syi'iran Nasehat dan Relevansinya dengan Tujuan Pendidikan Islam}

Syi'iran nasehat yang terdiri dari 62 bait karya KH. R. Asnawi, secara garis besar mengandung pendidikan akhlak kepada manusia. Yaitu mahmudah, artinya perbuatan yang terpuji dan harus dijalankan oleh manusia, dan mazmumah, yaitu perbuatan tercela yang harus dijauhi oleh umat manusia

Dari uraian syi'iran nasehat, dapat diambil garis-garis besar tentang akhlak, yaitu, pertama, akhlak yang terpuji terdiri dari Ar-Raja' seperti membaca salawat dan salam atas Nabi Muhammad, keluarganya dan para sahabatnya. Berbuat amal kebajikan yang 
berupa Al-Imu dan Al-Amal. Lemah lembut dalam berbuat atau at-tarabum. Riyadhah atau berusaha dengan sungguh-sungguh. Tawadu', atau rendah diri. Muhasabah, atau instropeksi diri. Khidmahnya istri pada suami. Kedua, Akhlak yang tercela terdiri atas malas, sombong atau takabur, ujub atau menganggap dirinya baik. Zakiyah An-Nafs atau merasa dirinya bersih, Sum'ah atau merasa dirinya hebat, merokok dan menginang yang menurut KH. R. Asnawi ada Madharahnya dan mendatangkan Mafsadah. KH. R. Asnawi menyusun sebuah syi'ir yang diberi nama Syiiran Nasehat ini merupakan bentuk kepeduliannya kepada anak dan cucunya serta umat Islam dalam rangka pembentukan akhlak atau perbuatan yang mulia.

Nilai-nilai pendidikan akhlak dalam Syïiran Nasehat masih sangat sedikit, walaupun sedikit tetapi nilai-nilai tersebut sangat berarti dan dapat dijadikan sebagai pijakan bagi kaum muslim pada umumnya, dan pada anak cucu KH.R Asnawi khususnya sebagai landasan agar dapat berakhlak mulia dan agar dapat hidup bahagia baik di dunia maupun di akhirat.

Adapun wujud relevansi niai-nilai pendidikan akhlak dalam Syïiran Nasehat dengan tujuan pendidikan Islam adalah bahwa Syiiran Nasehat berisi tentang pendidikan akhlak. Sedangkan tujuan pendidikan Islam tidak akan dapat tercapai kecuali dengan adanya pendidikan akhlak, sebagai penyeimbang dari iman dan amal, seperti dalam bait :

\section{Sebab mulyane menungso iku - benturing topo baguseng laku}

Bait diatas menjelaskan bahwa seseorang akan mendapatkan kemuliaan baik di dunia maupun di akhirat, dengan melakukan riyadhah dan menjalankan akhlak-akhlak yang mulia. Hal ini sesuai dengan tujuan pendidikan Islam yaitu terbentuknya kepribadian muslim yang berakhlak mulia dan mendapatkan kebahagiaan serta kemuliaan di dunia maupun di akhirat.

\section{Kesimpulan}

Berpijak pada rumusan masalah dari penelitian yang berjudul "Nilai-nilai Pendidikan Islam dalam Karya-karya KH. R. Asnawi Kudus (Telaah atas Kitab Jawab Soalipun Mu'taqad, Fasalatan dan Syi'iran Nasehat)", dapat disimpulkan bahwa kitab Jawab Soalipun Mu'taqad karya KH. R. Asnawi memuat tentang nilai-nilai pendidikan keimanan, yang diantaranya adalah iman kepada Allah dan iman kepada para Rasul. Iman kepada Allah, 
disini dijelaskan dengan cara menguraikan sifat-sifat Allah, yaitu sifat wajib, mustahil dan jaiz kesemuanya berjumlah 41, serta menunjukkan dalil-dalilnya, baik dalil aqli maupun dalil naqli. Sedangkan iman kepada Rasul, dijelaskan dengan cara menguraikan sifat-sifat para Rasul, yaitu sifat wajib, mustahil dan jaiz yang kesemuanya berjumlah 9, dan hanya menunjukkan dalil aqlinya saja. Jadi, dari jumlah sifat-sifat Allah dan sifatsifat para Rasul, kesemuanya berjumlah 50 .

Pendidikan keimanan dalam kitab tersebut belum menjelaskan tentang pendidikan keimanan secara keseluruhan antara lain pendidikan keimanan pada Malaikat, Kitab, Hari Akhir, Qodha' dan Qodar, Walaupun KH.R Asnawi belum menjelaskan keseluruhan dari pendidikan keimanan, Namun pendidikan keimanan dalam kitab Jawab Soalipun Mu'taqod sangat diminati dan berarti bagi masyarakat kudus dan sekitarnya, hal ini dapat di lihat pada madrasah-madrasah diniyah yang sampai sekarang masih menggunakan kitab tersebut. Kitab jawab soalipun mu'taqod diperuntukkan bagi anak-anak dan orang yang tingkat keimananya masih lemah. Hal ini sesuai yang tertulis dalam kitab tersebut halaman 4, yaitu tentang kewajiban pertama kali bagi manusia, yaitu mengetahui sifat-sifat Allah, bukan mengetahui dzat-Nya.

Kitab Fasalatan karya KH. R. Asnawi adalah sebuah karya sastra pesantren yang bertuliskan arab pegon dan memuat nilai-nilai pendidikan ibadah, di antaranya adalah tata cara melaksanakan ibadah salat, mulai dari sunah-sunnah sebelum salat, syarat syahnya salat, perkara yang membatalkan salat sampai rukun-rukun salat, serta penjelasan tentang salat-salat sunnah yang dianjurkan oleh Allah dan Rasul-Nya, di antaranya adalah salat rawatib, tahajud, dhuha dan lain-lain. Namun Kitab fasholatan tersebut belum mencerminkan pendidikan ibadah secara keseluruhan, karna dalam islam pendidikan ibadah bukan hanya sholat saja, melainkan ada pendidikan ibadah yang lain, seperti: muamalah, puasa, zakat, haji dan lain-lain. Walaupun kitab fasholatan belum menerangkan semuanya tentang pendidikan ibadah, tetapi kitab tersebut sangat berarti bagi masyarakat kudus pada zaman itu sampai sekarang, khususnya bagi anakanak. Menurut KH.R Asnawi pendidikan ibadah yang berupa sholat itu penting sekali, Ia mengingatkan pada kaum muslim dan anak-anaknya untuk selalu mengerjakan sholat lima waktu, Karna tanpa mengerjakan sholat kaum muslim akan merugi. 
Syi'iran Nasehat karya KH. R. Asnawi adalah sebuah karya sastra pesantren dalam bentuk nadhoman yang memuat nilai-nilai pendidikan akhlak, baik akhlak Mahmudah maupun akhlak Madzmumah. Akhlak Mahmudah yang terdapat pada syi'iran nasehat ini adalah Ar Raja', mengharapkan rida Allah dan syafaat Nabi-Nya, berbuat amal kebajikan, lemah lembut dalam berbuat atau at-tarahum, riyadhah atau berusaha dengan sungguh-sungguh, tawadhu', rendah diri, muhasabah, introspeksi diri, khidmahnya istri pada suami. Sedangkan akhlak madzmumah yang terdapat pada syi'iran nasehat ini adalah malas, sombong, ujub, Zakiyah An-Nafs atau merasa dirinya bersih, sum'ah, merokok dan menginang.

Ternyata nilai-nilai pendidikan akhlak dalam syiiran nasehat masih sedikit, walaupun sedikit namun nilai-nilai tersebut sangat berarti dan dapat dijadikan pijakan bagi kaum muslim seta anak cucu KH.R Asnawi sebagai landasan agar dapat berakhlak yang mulia dan agar dapat hidup didunia maupun di akhirat.

Nilai-nilai pendidikan Islam dalam karya-karya KH. R. Asnawi, yang di antaranya adalah nilai-nilai pendidikan keimanan dalam kitab jawab soalipun mu'taqod, nilai-nilai pendidikan ibadah dalam kitab fasholatan, nilai-nilai pendidikan akhlak dalam syiiran nasehat itu semua masih relevan dengan tujuan pendidikan Islam pada masa sekarang ini. Hal ini dapat dilihat dari inti tujuan pendidikan Islam yang terfokus pada terbentuknya kesadaran terhadap hakikat manusia sebagai hamba Allah yang diwajibkan menyembah kepada-Nya. Melalui kesadaran ini pada akhirnya ia akan berusaha agar potensi dasar keagamaan (fitrah) yang ia memiliki dapat tetap terjaga kesuciannya melalui keimanannya ibadahnya dan akhlaknya, sehingga ia hidup dalam keadaan selalu beribadah pada Allah, selalu menjalankan akhlak yang mulia serta selalu beriman sampai akhir hayatnya. 


\section{Daftar Pustaka}

Hidayat, Komaruddin, 1996. Memahami Bahasa Agama: Sebuah Kajian Hermeneutika, Jakarta: Paramadina.

Ikhsan, Fuad, 2005. Dasar-Dasar Kependidikan, Jakarta: Rineka Cipta.

Mansur, 2001. Dirkursus Pendidikan Islam, Yogyakarta: Global pustaka.

Munzier, Heri Noer Aly, 2003. Watak pendidikan islam, Jakarta: Friska agung insani.

Nasir, Mahmud a, 1991. ISLAM, konsepsi dan sejarahnya, Bandung: Remaja rosda karya.

Rosyid, Moh, 2004. Ilmu pendidikan[sebuah pengantar] menuju bidup prospektif, Semarang: UPT.Unnes Press.

Sanaky, Hujair AH., 2003. Paradigma Pendidikan Islam: Membangun Masyarakat Indonesia, Yogyakarta: Safiria Insania Press dan MSI. 